\title{
CONVERSANDO, DANÇANDO E RECRIANDO HISTÓRIAS Processo de Criação Colaborativo com a Terceira Idade
}

\section{TALKING DANCING AND RECRIATING STORIES Collaborative Creation Process with old-edged}

\author{
Renata Bittencourt Meira ${ }^{1}$
}

\begin{abstract}
Resumo
Descrição de uma montagem teatral realizada de modo colaborativo com um grupo de idosas na cidade de Paulínia. São apresentadas as estratégias utilizadas para a realização de uma montagem teatral original e significativa. $O$ texto mostra a constituição do grupo, 0 levantamento do material cênico e os temas abordados no espetáculo. A arte é concebida como proponente de um estado de criação e o fazer artístico se dá na complexidade do campo cultural contemporâneo.
\end{abstract}

Palavras-chave: artes populares, bricolagem, curso de teatro, montagem, performances culturais

Resumen

Descripción de una producción teatral realizada en colaboración por un grupo de personas de edad en la ciudad de Paulinia. Se presentan las estrategias utilizadas para llevar a cabo una producción de teatro original y significativo. El texto muestra la constitución del grupo, el material escénico levantado, y los temas tratados en el espectaculo. El arte se concibe como un proponente de un estado de la creación artística y en la creación es dada la complejidad del ámbito de la cultura contemporánea.

Palabras clave: artes populares, bricolaje, curso de teatro, montaje, performances culturales

\section{Abstract}

Description of a theatrical spetacle held in a collaborative way with a group of elderly women in the city of Paulínia, in São Paulo. The strategies used to perform an original and significant theatrical spetacle are presented. The text shows the constitution of the group, the survey of the scenic material and the themes addressed in the show. Art is conceived as a proponent of a state of creation and the artistic making takes place in the complexity of the contemporary cultural field.

Key-Words: Popular arts, Bricolage, Course of theater, Spetacle, Cultural performances

\footnotetext{
${ }^{1}$ Docente, Brincante, Diretora, Pesquisadora. Universidade Federal de Uberlândia; professora; renatameira@ufu.br.
} 
Expressar cenicamente emoções de vidas já longas é reviver estas emoções e, desta maneira, procuramos mostrar uma perspectiva idosa da vida. ${ }^{2}$

O estudo de processos de criação para realização de montagens teatrais na interação intercultural é um importante campo de conhecimento para as artes contemporâneas. Para conhecer e entender a multiplicidade de expressões e procedimentos de criação em teatro, na fricção das diferenças culturais, é preciso saber sobre cada um destes processos que constituem esta multiplicidade. Este trabalho foca a descrição de uma montagem teatral realizada de modo colaborativo com um grupo de idosas numa instituição municipal e gratuita de Arte e Cultura no município de Paulínia. O texto aborda o contexto em que o trabalho foi realizado, as atividades de constituição e conhecimento do grupo, a montagem da peça e a circulação do trabalho dinâmico e continuamente atualizado, por dois anos.

Conversando, dançando, cantando e contando histórias um grupo de vinte e cinco idosas, com idade entre 51 a 87 anos, criaram e apresentaram diversas vezes o espetáculo Todo Brasileiro tem uma História Escondida. Esta montagem foi desenvolvida em oficinas de teatro, coordenadas por Renata Meira ${ }^{3}$ no Centro de Integração das Artes - CIARTE - da Prefeitura Municipal de Paulínia, Estado de São Paulo, no qual são oferecidas aulas de artes gratuitas para diversas faixas etárias. Esta descrição parte do ponto de vista da coordenação do trabalho. As oficinas aconteciam semanalmente, com duas horas de duração, foi um processo dinâmico desenvolvido em dois anos, em 1999 e 2000. O poder público municipal, naquela gestão ${ }^{4}$, investia recursos na qualidade de vida da população. Alfabetização, esporte, dança e teatro eram atividades oferecidas para os idosos, que também participavam com interesse de eventos como a Semana do Idoso de Paulínia ou o Dia dos Pais. Estas atividades regulares e estes eventos formavam uma rede de encontros e relações. As pessoas que participaram do processo, portanto, já se conheciam de outras atividades.

Vinte e cinco idosas, todas mulheres, iniciaram o trabalho. As integrantes do grupo tinham diferente escolaridade, vinham de diferentes classes sociais e origens diversas, a maioria passou parte da vida na zona rural. A maioria das integrantes do grupo havia participado anteriormente da montagem de Morte e Vida Severina com outro diretor/professor. Uma experiência teatral realizada a partir do texto. Um texto longo e difícil. Grande parte das idosas eram analfabetas e o processo foi dolorido, várias desistiram. A proposta do diretor \professor exigiu a memorização de cada palavra do texto. Esta experiência com o texto como pilar central do trabalho era a referência de teatro naquele contexto, muito diferente da proposta que iríamos desenvolver. A montagem do texto de João Cabral de Melo Neto estava centrada no texto dramático e contou com uma direção centralizadora. Havia um sentimento conflituoso acerca desta experiência. Por um lado o orgulho de realizar uma tarefa difícil. Apresentar o texto Morte e Vida Severina na íntegra é um desafio até para profissionais de teatro. Para estas idosas, a realização e a apresentação do trabalhao foi bastante significativa. A montagem apresentou o texto na íntegra. As atrizes que chegaram ao fim da montagem e apresentaram a peça se sentiram vencedoras. Ao mesmo tempo,

\footnotetext{
${ }^{2}$ Renata Meira: Texto do folder do trabalho elaborado por e compartilhado com todas.

${ }^{3}$ Renata Meira foi contratada como professora de Teatro no CIARTE e trabalhoou com grupos infantis, juvenis, adultos e idosos de 1998 a 2000.

${ }^{4}$ Prefeito Adélsio Vedovello - 01\01\1997 a 31\12\2000.
} 
outro sentimento diferente da vitória estabeleceu uma emoção conflitante em cada participante dos processos. A memória de um processo doloroso, no qual os limites de cada uma foram abordados com sofrimento, estava presente nos depoimentos das atrizes. Foi grande o esforço para conseguir realizar uma peça de teatro nos padrões propostos. A experiência e as referências cênicas das integrantes do grupo foram pouco valorizadas. Neste contexto, foi dado início à uma outra prática com o objetivo de estimular o estado criativo por meio de um processo diferente de montagem teatral. Muitas vezes fui questionada: "Quando vamos fazer teatro?".

A primeira meta foi conhecer e, ao mesmo tempo, constituir o grupo. A proposta de montagem deveria ser encontrada nas relações de grupo. A encenação estava por ser criada, deveria apresentar movimentos e histórias significativas nos quais o grupo tivesse intimidade suficiente para mantê-la viva, dinâmica. Os primeiros passos do trabalho foram os passos do cacuriá e do caroço, danças populares do Maranhão ${ }^{5}$, simples e com o ritmo animado. A cada encontro dançávamos e conversávamos sobre a vida de cada uma. As canções selecionadas se referiam à vida simples do homem rural. Cortá capim, rancá batata, baná o fogo, embalar neném, estimulavam as lembranças de um passado rural, povoado de causos e lendas, das plantações de café e de arroz com os filhos pequenos, do fogão à lenha, das tocas de tatu, do pai ou marido alcoólatra, das noites escuras nas quais surgiam lobisomens.

Nestas conversas Maria Antônia, alagoana, lembrou-se do Jaraguá, um grande bicho de pano que corria atrás das crianças. Resolvemos confeccionar um Jaraguá para participarmos da VIII Semana do Idoso de Paulínia - SEMI-Idoso cidadão: conquistando novos passos. Assim, além de dançar, cantar e contar histórias, passamos a costurar, moldar e pintar nosso Jaraguá, que ficou com 12 metros de comprimento. Junto com ele fizemos uma Maricota, corpo de balaio e cabeça de papel, para desfilarmos na SEMI. Foi uma alegria e um sucesso, o grupo ganhava intimidade e expressões próprias.

O universo evocado pelas cantigas e danças compartilhadas, criou um substrato cultural e direcionou as conversas e os desejos. "Se na dança o corpo é proeminente, se o movimento é o pensamento do corpo e se a cultura é também o nome que se dá aos contornos do agir do corpo, temos então, na dança, um importante veículo discursivo por meio do qual opera uma epistemologia" (SILVA: 2012, p. 2) . A epistemologia em que mergulhamos valorizou a experiência compartilhada da dança, numa prática em que cada um faz do seu jeito, mas todos fazem juntos. A brincadeira e a participação de todas passaram a ser constantes nos encontros. A descontração e a improvisação foi se instaurando e todas fomos nos sentindo em casa.

Contação de história, bonecos gigantes, música de viola, histórias de encantamentos, histórias da vida na roça e as festas de religiosidade popular foram as principais fontes expressivas do processo. Aos poucos o envolvimento com estas atividades aquietou a ansiedade por fazer o teatro como havia sido feito anteriormente. A prática questionava o padrão do que era reconhecido como Teatro. Esta transformação foi importante, pois o conhecimento cênico acumulado no decorrer da vida de cada uma pode ser desvelado. A perspectiva cênica criada pela ludicidade e por referências culturais significativas substituiu uma perspectiva padronizada. A noção de Teatro foi sendo expandida sem teorizações, a partir da realização de propostas

\footnotetext{
${ }^{35}$ São práticas de "dançar, cantar e batucar" (FU-KIAU, Bunseki apud LIGIERO, Ligiero:2011 ), tocadas e dançadas por mulheres Caixeiras do Divino Espírito Santo no estado do Maranhão. Cantar-danças-batucar é um continuum das performances de motrizes africanas, de acordo com o filósfo congolês unseki Fu-Kiau.
} 
cênicas que emergiram do encontro e da troca entre as pessoas envolvidas.

O primeiro trabalho cênico do grupo foi, então, a construção coletiva de dois bonecos gigantes inspirados no Jaraguá, proposto por Maria Antônia de Alagoas, e uma Maricota do interior de São Paulo, sugerida pela coordenação do grupo. 0 corpo da Maricota foi feito com uma cesta utilizada pelo pessoal da jardinagem da prefeitura, para coletar folhas. A cesta dava o formato arredondado do corpo de Maricota que tinha braços de tecido e um cabeção de papel marchê. O corpo da Jaraguá foi feito com um grande corte de chita, estruturado com doze bambolês, fazendo um bicho de doze metros de comprimento. A cabeça do Jaraguá, também feita de papel marchê, era articulada, uma grande mandíbula permitia que o bicho abrisse e fechasse a boca. Jaraguá e Maricota desfilaram no cortejo do dia do Idoso da cidade de Paulina. Enquanto o grupo se envolvia em costurar, moldar, pintar e estruturar os bonecos para participar do desfile na cidade de Paulina, era estimulado a contar histórias de vida e histórias da vida. Eram compartilhadas também histórias, histórias, piadas, danças e músicas. Passagens biográficas eram contadas com detalhes. O imaginário mágico do universo rural surgia em várias histórias. As relações de família que surgiam nos depoimentos apontavam um lugar submisso da mulher e mostravam a educação controladora que viveram. Também ficou evidente que o casamento era o destino de todas estas mulheres, na perspectiva familiar.

Os bonecos ganharam forma e o grupo passou a dançar junto cacuriás e caroços. A memória dos atuantes, a dança e a relação de grupo ganharam significado naqueles encontros. Às proposições da professora\diretora foram enriquecidas com proposições vindas da experiência e da imaginação dos integrantes do grupo. O processo de criação foi estimulado por atividades criadas a partir deste universo cultural e social que se apresentava. Este primeiro trabalho resultou na participação dos idosos com os bonecos nas ruas de Paulínia, e resultou também num grupo. Um grupo que dançava e cantava. Um grupo no qual histórias de vida e histórias imaginárias foram compartilhadas. Um grupo composto apenas por mulheres. A grande maioria nascida na roça. Todas com história de alcoolismo na família, havia marido, pai ou filhos alcoolatras.

O material cênico estava sendo levantado. Danças, relações interpessoais, situações de conflito, personagens mágicos, músicas entre outros materiais passaram a ser articulados cenicamente e a constituir a matéria a ser trabalhada em estado criativo. Este estado em que o atuante participa criativamente, foi evocado das práticas culturais envolvidas: as histórias e histórias, as músicas e as figuras, bem como o dançar, cantar, batucar das caixeiras. O estado criativo é uma realidade da cultura popular. Os brincantes, foliões e dançadores, por exemplo, rememoram e recriam as performances culturais. Nestas performances, há uma estrutura cênica que é permeada de alterações, variações, adaptações e improvisos. 0 contexto no qual o espetáculo acontece, como acontecimentos de rua e o público, influencia cada apresentação. A bricolagem realizada na atualização de tradições (LEVI STRAUS: 1989), com suas variações e adaptações (BURKE: 1989), é uma prática em estado de criação.

Artistas brasileiros de vanguarda, dentre os quais destaca-se Hélio Oiticica, também desenvolveram a arte como proponente deste estado de criação (FAVARETO, 1992). A trajetória de Oiticica, mostra que seu fazer artístico se tornou mais um gerador do estado de criação do que realizador de obras para apreciação. Além de fazer arte, Oiticica refletiu e escreveu sobre sua arte e fez 
do fazer artístico uma ideologia, uma escolha de vida. Nas palavras de Oiticica a arte torna-se "um espaço estético de vivências descondicionantes", permissiva, provoca sensações ambíguas e mobiliza emoções e pensamentos. Tecendo cultura popular com vanguarda brasileira foi desenvolvido o teatro com os idosos em Paulínia, valorizando a vida criativa, concebendo o mundo de maneira múltipla e edificando a aceitação da diversidade. Um pressuposto importante é a perspectiva da arte como um fazer que estimula um estado criativo.

O teatro com idosos traz especificidades que merecem uma atenção criativa para que cada ator possa dar o máximo de si, mesmo em condições adversas de saúde e humor. Faltas, desistências e novos adeptos são circunstâncias que se repetiam. A preocupação com a saúde ocupava muito o tempo dos idosos. Freqüentemente a família tem a tutela financeira, a guarda legal por incapacidade ou ainda depende do trabalho, formal ou informal, do próprio idoso. As famílias muitas vezes depende do dinheiro da aposentadoria e da ajuda dos idosos para olhar os filhos, cozinhar ou arrumar a casa. Poucas vezes essas atividades têm o reconhecimento adequado e a auto estima do idoso é muitas vezes baixa. Convivemos com tratamentos, viagens, doença de parente, demandas familiares, entrada e saída de membros durante o processo de criação, ensaio e mesmo na seqüência das apresentações. A estrutura da montagem permitia estas ausências e novas participações. Entendemos e consideramos que a composição do grupo variava.

A criação coletiva acompanhou a concepção de arte como motivadora de um estado de criação e seguiu o processo de criação popular na elaboração da montagem. Hélio Oiticica e Peter Burke ofereceram um solo firme por onde caminhamos com o teatro popular e criativo dos idosos de Paulínia. As formas e processos de composição da cultura popular apresentados por Peter Burke foram analisados na dissertação de mestrado $O$ Ciclo das festas: uma leitura cênica da dança do fandango e das festas populares de Cananéia, litoral sul do Estado de São Paulo (MEIRA, 1997). Naquele trabalho tal análise contribuiu para ao entendimento do fandango e apontaram propostas objetivas para a leitura cênica realizada no processo de pesquisa. Burke analisa as manifestações populares da Europa no início da Idade Moderna, entre 1500 e 1800, propondo a existência de um repertório de formas e convenções da cultura popular e a existência de uma estrutura de composição organizacional. A análise de Burke acerca do processo de criação popular deu a base para a realização de processos de criação cênica, tanto o desenvolvido no trabalho de mestrado citado acima, quanto o desenvolvido com as idosas. Podemos sintetizar o processo utilizado, considerando a análise da criação popular, como uma estrutura fixa que oferece a base para improvisações, variações, repetições, redundâncias e um repertório recorrente, revivido por cada sujeito com características expressivas individuais. Neste trabalho a história composta num processo de criação coletiva formava a estrutura fixa que era a base de improvisações, variações, repetições e novas criações.

O processo de criação do espetáculo Todo o Brasileiro tem uma História Escondida, criação coletiva, partiu de conversas sobre a história de vida dos idosos e da prática da dança brasileira. Este processo se baseou no entendimento da criação popular como uma maneira de absorver a dinâmica do grupo, incluindo novas histórias e personagens na medida em que as apresentações apontavam novos caminhos e que os integrantes do grupo traziam novas propostas, lembranças, idéias, movimentos, vontades e coragens. A memória foi um campo de onde colhemos fragmentos de vida e da alegoria que preenche os pensamentos e a visão 
de mundo. A dança fazia o corpo entrar em movimento junto com a memória, dançando o plantar, o colher, o cortar capim, a formiga, o banar o fogo, entre outros temas que fazem parte da vida das idosas do grupo. Das lembranças vieram as situações dramáticas que constituem a montagem. A família em casa, o pai fumando cigarro de palha e a mãe fazendo crochê. O namoro proibido nas festas dos mutirões, a cozinha com o fogão a lenha e os tachos, as plantações com as sementes e o arado, os bailes e outras situações vieram da memória, nas conversas de mãos ocupadas com os bonecos e de corpos cansados da dança divertida do cacuriá e do caroço. Os dramas familiares com seus bebes raptados pelo lobisomem. As garrafadas, a defumação e as benzedeiras também se fizeram presentes. Duas benzedeiras, uma de preto e outra de branco, se desafiavam em seus poderes. Maura lembrou-se de um verso para espantar lobisomem que entrou em cena:

\section{Cruz encontra, cruz em monta \\ Que o demônio não me encontra \\ Nem de noite, nem de dia \\ E nem em pin de meio dia (anotaçõe de aula)}

Junto com os versos de poder mágico, surgiam também situações cômicas. O texto ia sendo criado e o roteiro ia sendo escrito. Seguíamos o roteiro de acordo com as criações, estabelecíamos a cada ensaio uma estrutura fixa. Entretanto, cada intérprete tinha a liberdade para recriar, adicionar, repetir, enfim, variar como no processo de criação popular (BURKE: 1989). Da cultura popular veio também a relação com o público. Algumas falas, como a de Sá Catarina a benzedeira de branco, interpretada por Maria Antônia, eram dirigidas diretamente para a platéia:
Boa tarde querido público, hoje vou ensinar uma garrafada que eu aprendi com a minha bizavó, cura qualquer doença, acaba com qualquer mal,levanta qualquer defunto. Preste atenção para não esquecer nenhum ingrediente: perna de pulga viúva, cabo de carrapato capado, chifre de vaca mocha... (Anotações de Aula)

$\mathrm{Na}$ época da congada de Uberlândia ${ }^{6}$, em novembro, foi apresentado um registro das festas mineiras. Assistimos ao vídeo com os diferentes ternos de Congada: Moçambique, Congo, Marinheiros e Catupés. As imagens do vídeo acordavam novas imagens da memória. Enquanto isso também dançávamos o Congo, olhando as danças de Uberlândia, ouvindo e pulsando com as músicas do Congo de Goiabeira no Espírito Santo. Não havia a intenção de reproduzir ou mesmo representar alguma performance cultural. Por isto as imagens podiam ser de local diferente das músicas. Os fragmentos da performance, como música, passos, desenhos coreográficos, eram apresentados ao grupo como estímulos para criação cênica. O Congado existe em muitas partes do Brasil. As imagens de Uberlândia e a música do Espírito Santo sacaram da memória de Manuelina "a Congada" de Morungaba, uma cidade perto de Paulínia, onde ela nasceu. Incluímos no roteiro a Congada da maneira como Manuelina nos ensinou.

Durante um dos ensaios em que fizemos a Congada, Dona Carmem, a integrante mais velha do grupo com 96 anos declarados, 15 filhos, 54 netos e 17 bisnetos, postou-se no papel de Rainha do Congo. Sem dizer nada a ninguém assumiu atitudes diferentes da proposta do grupo. Depois, em conversa, soubemos que foi como uma revelação, brotou da memória de Dona Carmem o Congado do qual seu pai era capitão e ela assumiu a postura e os

\footnotetext{
${ }^{6}$ O processo aconteceu em Paulínia, mas a coordenadora do processo morava em Uberlândia, viajava semanalmente para trabalhar com os cinco grupos de teatro no CIARTE.
} 
movimentos de Rainha. Assim o nosso Teatro ganhava corpo. Cenas significativas surgiam, incluindo no roteiro promessas, receitas de comida, brigas de casal por causa da cachaça durante o baile do mutirão e até exorcismo. O baile era um acontecimento recorrente nas histórias de cada uma. Definimos que faríamos uma cena de baile. Para esta cena do baile Aninha trouxe seu violão e além de tocar o Forró da Farinhada, "tava na peneira, eu tava peneirando", apresentou algumas composições próprias que incluímos no enredo da história. Então, nosso baile foi feito com música ao vivo.

A estrutura geral do espetáculo utilizou as danças do Cacuriá, Caroço, Congado e Forró, como uma espécie de coro. Eram passagens de cenas, ilustrando ou dinamizando situações dramáticas, as danças compunham a história. O coro das danças era simples para os novos participantes. Com esta estrutura podíamos aceitar novos integrantes, os quais participavam imediatamente das apresentações compondo primeiro o coro e depois interferindo na história encontrando seu espaço, criando sua cena. O baile ofereceu oportunidade de agregação de pessoas e personagens. Com Aninha ao violão e o coro com as peneiras, compusemos a primeira versão do baile, no qual os pares entravam um a um, até que o casal principal, do namoro proibido, iniciava seu diálogo. Maria Antonia, a alagoana, logo criou um bêbado, "porque não existe baile sem bêbado". Quando Roberta entrou no grupo, o espetáculo já estava bem estruturado e Maria Antônia convidou Roberta para ser a mulher do bêbado, na qual batia e abandonava por causa da cachaça. Depois de alguns meses entrou no grupo Seu Antônio, esposo de Miriam, que fez o amigo do bêbado. A cena do bêbado foi enriquecida com situações cômicas, todas criadas pelos integrantes do grupo. Miriam era costureira e fez uma cueca vermelha de bolinhas brancas para Seu Antônio, na briga entre os bêbados a calça caía e o "amigo do bêbado" saia de cena de cueca de bolinhas. Roberta, a mulher do bêbado, inverteu a lógica da violência ao peidar para os tapas que recebia do marido. Nesta dinâmica o espetáculo se mostrou receptivo, mobilizando emoções e pensamentos, proporcionando a oportunidade de criação. Os novos integrantes eram bem recebidos, acolhidos no próprio espetáculo, a vida criativa era vivenciada com prazer e a diversidade era entendida como riqueza.

A coexistência de universos distintos é uma condição contemporânea incorporada ao processo de criação deste espetáculo. Foi evidenciada através de ações simbólicas e elementos estéticos. Situações do passado, do presente e do imaginário de cada integrante do grupo fizeram parte do processo de criação e do espetáculo apresentado. 0 urbano e o rural, a memória e a imaginação, o passado e o presente são distintos universos que compuseram o espetáculo. O Congado do grupo se fez da somatória de manifestações de regiões diversas, no caso, Minas Gerais, Espírito Santo e São Paulo. A peneira da farinhada, dançada no baile, era a mesma de peneirar o café. A liberdade de criação permeou o fazer teatral. A dança popular estimulou a memória que trouxe histórias apresentadas e recriadas pelos próprios atores protagonistas da vida real. A bricolagem e o hibridismo fizeram parte da metodologia. O limite de cada idoso foi respeitado, a criatividade e a disposição em estar junto em cena foram valorizadas. O grupo se constituiu de sujeitos, de indivíduos que se viam num mesmo espelho que refletia tantas histórias diferentes. 


\section{REFERÊNCIAS}

ANOTAÇÕES DE AULA. MEIRA, Renata. Anotações dos encontros: planejamento e relatório das atividades. Paulínia: Relatório das Oficinas dia a dia. 2003.

BURKE, P. Cultura Popular na Idade Moderna. SP: Companhia das Letras, 1989.

CARDOSO, H. D. de F. O gesto, o canto e o riso: história viva na memória. SP: ECA/USP: tese de doutorado, 1990.

FAVARETTO, C. A invenção de Hélio Oiticica. SP: Edusp, 1992.

LÉVI-STRAUSS, Claude. Pensamento Selvagem (o). Papirus Editora, 1989.

LIGIÈRO, Zeca. Cantar, dançar, batucar. Corpo a corpo: estudos das performances brasileiras, $p$. 131-155.

MEIRA, R. B. O Ciclo das Festas: uma leitura cênica da dança do fandango e das festas populares de Cananéia, litoral sul do Estado de São Paulo. Campinas, SP: UNICAMP, dissertação de mestrado, 1997.

ORTIZ, R. A consciência fragmentada. RJ: Paz e Terra, 1980.

SCHELLING, V. A presença do povo na cultura brasileira: ensaio sobre o pensamento de Mário de Andrade e Paulo Freire. Campinas, SP: EDUNICAMP, 1990.

SILVA, Renata de Lima. A potência artística do corpo na capoeira Angola. ILINX-Revista do LUME, v. 2, n. 1, 2012.

Recebido: 07/09/2016

Aprovado: 01/10/2016

Publicado: $12 / 12 / 2016$ 